\title{
The Environmental Monitoring and Assessment Program (EMAP)-West-Summary of Activities and Accomplishments in South Dakota, 2000-2004
}

\section{Introduction}

$\mathrm{T}$ he Environmental Monitoring and Assessment Program (EMAP)-West was initiated in South Dakota in 2000 by the U.S. Environmental Protection Agency (USEPA). The two primary objectives of the surface waters component of EMAPWest were to (1) develop the monitoring tools (biological indicators, stream survey design, estimates of reference condition) necessary to produce unbiased estimates of the ecological condition of surface waters across a large geographic area of the West; and (2) demonstrate the effectiveness of those tools in a large-scale assessment. Although not specifically defined as an objective, data collected during EMAP-West also will help to establish a baseline for comparisons with data obtained from future monitoring efforts and could document changing biological conditions resulting from changing land-use or landmanagement practices associated with regulatory or restorative efforts.

EMAP-West is a partnership between USEPA, States, Tribes, and other interested parties in USEPA Regions 8, 9, and 10. In South Dakota, the principle EMAP-West cooperators include the USEPA, South Dakota Department of Game, Fish and Parks (GF\&P), and the U.S. Geological Survey (USGS). Other agencies such as the Natural Resource Conservation Service, the South Dakota Department of Environment and Natural Resources (SDDENR), State Conservation Districts, and various Tribal departments also have provided valuable expertise and assistance.

This fact sheet summarizes the activities and accomplishments associated with EMAP-West in South Dakota during 2000-2004. Efforts were focused on perennial streams that usually can be waded. Large rivers also were assessed during EMAP-West under the auspices of USEPA using boats and similar techniques, but are not included in the activities discussed here. Data-collection activities for wadeable streams were conducted under the auspices of USEPA in South Dakota during 2000 and by the USGS during 2001-2004. A more detailed description of EMAP-West activities and assessments in South Dakota is available in Heakin and others (in press).

\section{Background}

Historically, most of the data collected for the USEPA to evaluate the condition of our Nation's surface-water resources consisted of physical and chemical data, which were collected by States and Tribes using many different methods. These data have been compiled by USEPA and submitted to Congress in biennial reports called $305 \mathrm{~b}$ reports (for section $305 \mathrm{~b}$ of the Clean Water Act).

In the late 1980s, USEPA began to re-evaluate the methods previously used to determine the condition of the Nation's water resources. Several recommendations suggested that USEPA should collect data that could evaluate environmental trends and identify potential problems in their infancy (U.S. Environmental Protection Agency, 1987). This type of ecological "risk assessment" required development of a core set of indicators of ecological condition that could be incorporated into the bioassessment process.

Bioassessments largely consist of surveys involving the collection, identification, and enumeration of aquatic biota (algae, invertebrates, and vertebrates) inhabiting a waterbody. Bioassessments also often include enumeration and identification of riparian vegetation. Current (2005) thinking is that when bioassessment data are combined with chemical and physical data, the ability to estimate the overall condition of a waterbody is enhanced, thereby providing more validity and usefulness to water-resources assessments.

Physical changes occurring in a waterbody such as fluctuations in temperature and sediment concentrations, or chemical changes such as fluctuations in concentrations of nutrients or trace metals, can result from both natural and anthropogenic sources. Even subtle changes in physical or chemical conditions may stress more sensitive members of the aquatic community, causing a shift in biological integrity that favors the less sensitive and more tolerant aquatic organisms over those that are more sensitive and less tolerant, thus lowering species diversity. Generally speaking, a waterbody with good biological integrity has the capacity to support a diverse and balanced community of organisms that are representative of the composition found in the natural habitat of the area. Therefore, reliable bioassessment data are required to make meaningful assessments of biological integrity, which in turn, is essential for providing accurate evaluations of the condition of our Nation's surface-water resources.

In the 1990s, USEPA conducted research and monitoring demonstrations through several regional studies, including the Mid-Atlantic Highlands Streams Assessment study, that helped to develop and refine many of the bioassessment monitoring techniques and designs currently used by EMAP-West (U.S. Environmental Protection Agency, 2000). However, for EMAPWest, some novel tools still had to be developed, primarily to address the large environmental variability encountered throughout western States (U.S. Environmental Protection Agency, 1998). 
USEPA recognized that for the bioassessment information to be most useful, the data had to be collected in a consistent manner using similar techniques developed specifically to provide information for a core set of indicators. Subsequently, the USEPA developed a detailed Field Operations Manual for Wadeable Streams for EMAP-West (D.V. Peck and others, U.S. Environmental Protection Agency, written commun., 2000) along with training courses to ensure that EMAP-West data would be collected using a similar set of techniques and protocols that focus on a specific core set of indicators.

\section{Overview of the Study}

The target population for EMAP-West is all wadeable perennial streams in USEPA Regions 8, 9, and 10 excluding the "Great Rivers" (the Columbia, Snake, Colorado, and Missouri Rivers). Because it was neither economically feasible nor practical to sample all perennial streams within those regions, USEPA developed a probability design that randomly selected stream assessment sites that would be statistically representative of the surface waters in the West. This would allow for extrapolation of results for streams within each State and for streams in all regions that share similar ecological characteristics. EMAPWest also incorporated a systematic grid, which provides uniform spatial coverage, that ensures that each ecological resource is sampled in proportion to its geographical presence.
In South Dakota, bioassessments were conducted at two different site categories - randomly selected sites and candidate reference sites (fig. 1). A complete set of core ecological indicators established by USEPA were measured at each stream assessment site whenever possible. The ecological indicators measured include (1) physical habitat (channel and riparian characterization), (2) instream characteristics (vegetation and frequency of riffles and pools), (3) aquatic vertebrate assemblages (fish, amphibians, and crayfish) (fig. 2), (4) periphyton assemblages (algae), (5) benthic macroinvertebrate assemblages (aquatic organisms without backbones that can be seen with the naked eye), (6) field properties (water temperature, $\mathrm{pH}$, dissolved oxygen, specific conductance, and streamflow), (7) water chemistry (major ions and nutrients), and (8) fish tissue contaminants.

Field data were recorded on standardized field data sheets developed by USEPA's Western Ecology Division (WED) in Corvallis, Oregon (fig. 3). The completed data sheets were returned to WED where they were optically scanned to facilitate quick entry of the data into the database and to reduce data entry errors. The WED also was responsible for tabulating, reviewing, and verifying the large volume of stream assessment data generated by field crews participating in EMAP-West Study. Following verification, the data will be made available to the public on the EMAP-West Web site at http:/www.epa.gov/emap/ $\mathrm{html} / \mathrm{dataI} /$ index.html and archived in the USEPA's Storage

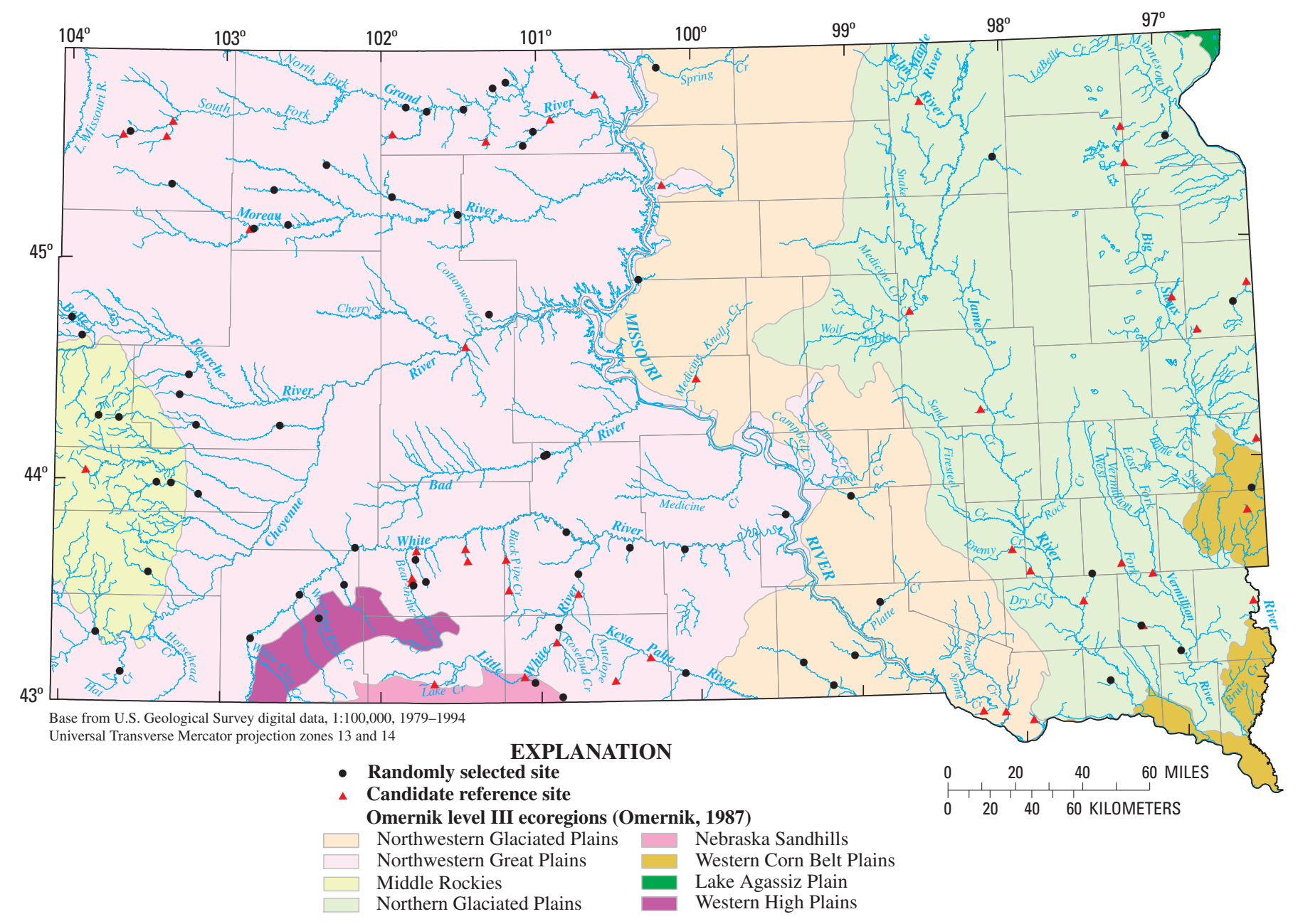

Figure 1. Locations of randomly selected sites and candidate reference sites visited during 2000-2004. 


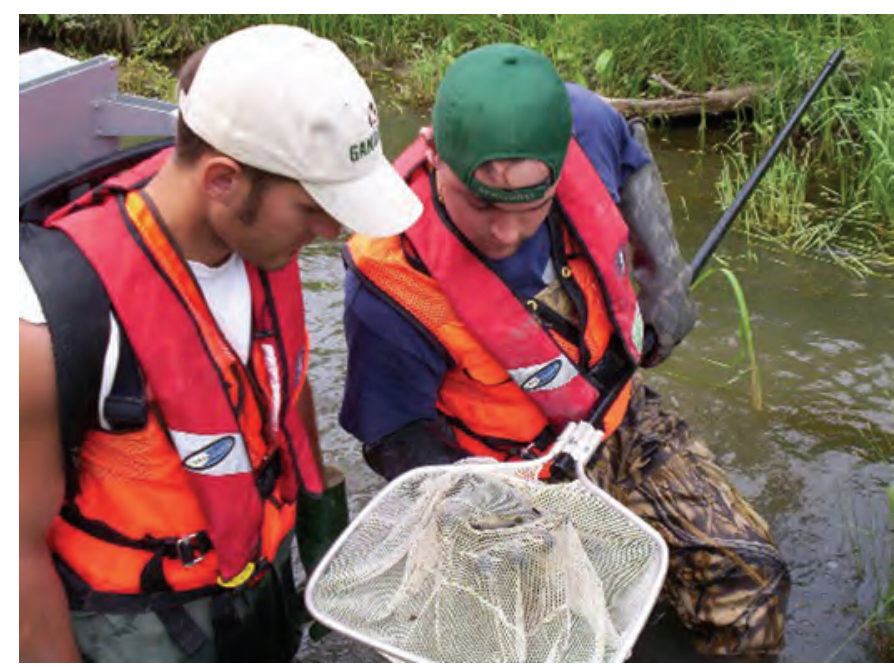

Figure 2. Field crew members collected aquatic vertebrate samples.

and Retrieval (STORET) database at http:/www.epa.gov/storet. The EMAP-West Web site provided above also contains a list of individuals that should be consulted prior to attempting data retrieval and acquisition.

\section{Randomly Selected Sites}

During 2000, sampling was completed by USEPA at 22 randomly selected sites. During 2001-2003, USGS and GF\&P completed sampling at another 42 randomly selected sites bringing the total number of randomly selected sites to 64 (fig. 1). Eighteen repeat assessments were done at 12 sites to provide estimates of important components of variability related to determining current status of the target population and trend detection (Chaloud and Peck, 1994). Alternate sites were identified and substituted for assigned sites that could not be assessed because reconnaissance visits indicated that they were unsafe (could not be waded), non-target, or dry, or because site access permission was denied.

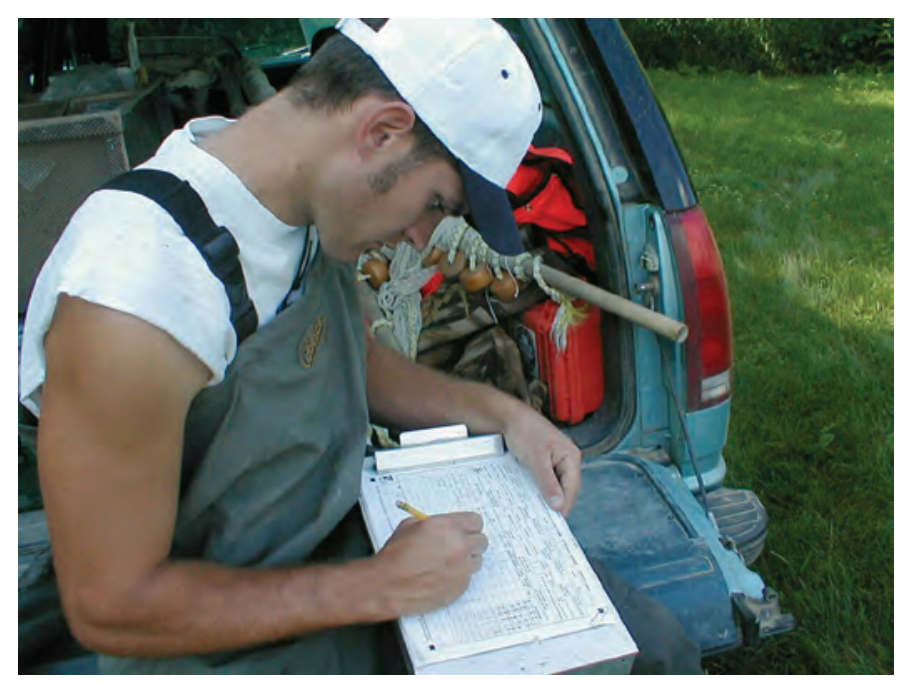

Figure 3. Field crew members completed field data sheets during EMAP stream-assessment activities in South Dakota.
Once coordinates for latitude and longitude had been obtained from the USEPA, the locations of the sites were plotted on topographic maps. Sites were then field visited to confirm that streams were representative of the target population and to determine the precise coordinates on the stream banks using maps and Global Positioning System (GPS) units. Later, a field crew returned to each site to establish the length of the stream reach (40 times the wetted width of the stream or a minimum length of 150 meters) and to conduct the assessment (fig. 4). Samples collected during stream assessments were generally shipped overnight to the USEPA for analysis. USEPA has established an "index" period for stream assessments in an attempt to reduce the effects of temporal variations at selected sites. The index period in South Dakota is between June 1 and August 31 and is the period when most field work was completed during the 5-year period 2000-2004.

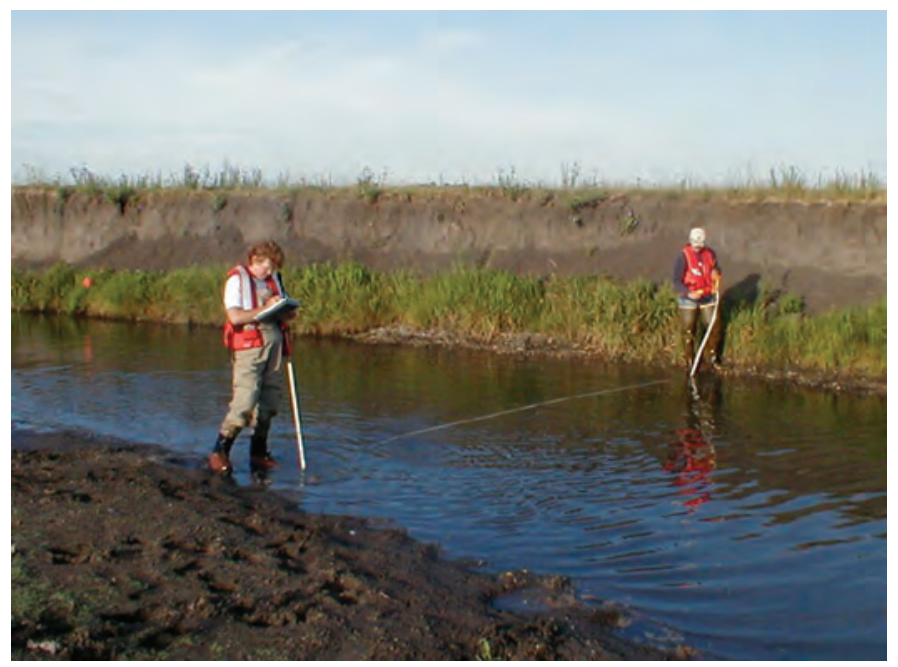

Figure 4. Field crew members assessed various watershed characteristics.

\section{Candidate Reference Sites}

In order to provide a means for assessing the relative overall ecological condition of the randomly selected sites throughout South Dakota, it was necessary to establish some standard or benchmark for comparison purposes. Furthermore, estimates of reference condition are specifically included as part of objective 1 for EMAP-West. In South Dakota, this objective was accomplished by establishing a network of reference sites that were selected for assessment because, after preliminary field reconnaissance, it was determined that they met an established set of selection criteria and appeared to have reasonable potential for representing the best available physical, chemical, and biological conditions within each of the four major Omernik Level III Ecoregions (Omernik, 1987) within the State (the Northern Glaciated Plains, the Northwestern Glaciated Plains, the Northwestern Great Plains, and the Middle Rockies) (fig. 1). During 2002-2003, USGS and GF\&P were primarily responsible for selecting reference sites for assessment. However, assistance with reference site selection was provided by personnel from various State and Federal agencies, Tribal representatives, 
various water-resource professionals, and other interested parties. In 2004, USEPA assigned a list of reference sites to USGS for assessment based on a new set of selection criteria that they recently had developed.

At the end of the field season in 2004, South Dakota's candidate reference site network included 45 sites. Thus, 109 stream assessments were completed (excluding repeat visits) during EMAP-West in South Dakota. As assessment data becomes available from USEPA, the data will be evaluated to determine if a site remains a viable candidate for the reference site network or if it should be removed.

\section{Benefits of the Study}

EMAP-West has and will continue to provide a wealth of valuable new bioassessment information for GF\&P and for other agencies, organizations, and decision makers in South Dakota and across the West. Specifically, in South Dakota, information relative to the spatial distribution of threatened and endangered species and invasive or introduced species of fish and plants will be available for many streams with little or no previous information (fig. 5). The State also will benefit by having a new set of environmental monitoring tools and techniques available and by having individuals familiar and experienced with implementing them to meet future monitoring requirements. Data collected during EMAP-West can serve as a baseline for future monitoring efforts and could be used to document changing ecological conditions resulting from either regulatory or restorative efforts, or to identify areas where additional or intensified efforts are needed. These data also may be useful for assessing trends for some ecological indicators.

Through EMAP-West, USEPA, USGS, and GF\&P have gained valuable information that can be used to more accurately assess the condition of our Nation's aquatic resources. Furthermore, bioassessment data obtained from EMAP-West could be used by SDDENR to develop a set of biocriteria for South

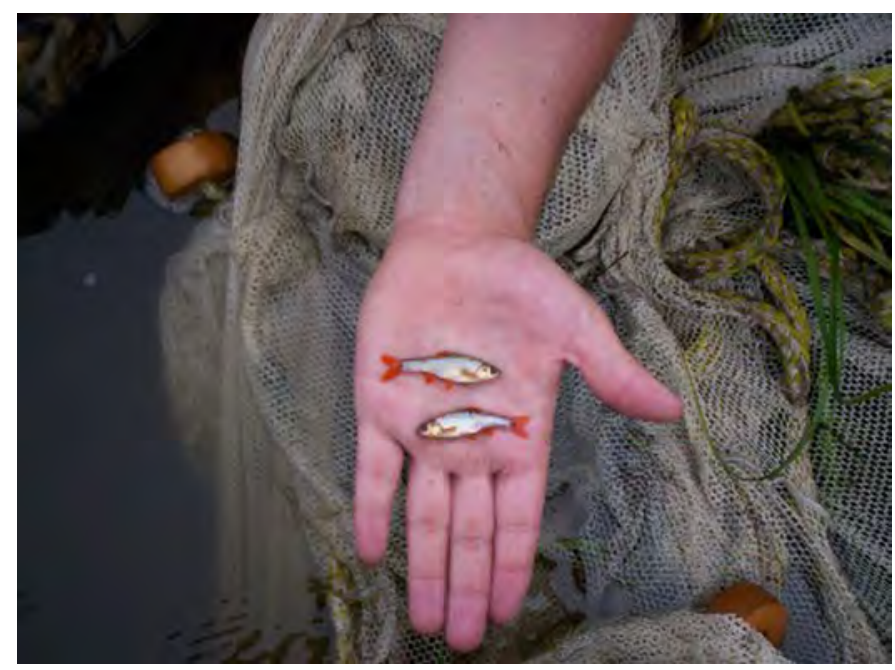

Figure 5. Field crew members collected Topeka Shiners (Notropis topeka) that currently appear on the Federal list of endangered species. Endangered or protected species were identified, photographed, and immediately returned to the stream.
Dakota's streams. Biocriteria are a set of narrative descriptions or numerical values that States and Tribes can include in their water-quality standards. The standards can be used along with the chemical and physical data routinely collected by States through their monitoring programs, to better manage water resources (U.S. Environmental Protection Agency, 2002).

The USGS also has benefited from EMAP-West by forming new partnerships and strengthening relationships by working cooperatively with various State agencies and through collaboration with the USEPA. The USGS has provided new and timely information concerning the condition of the State's natural resources that can be used in a variety of different ways at local, State, or regional levels to advance the science of ecological monitoring.

\section{References}

Chaloud, D. J., and Peck, D.V., eds., 1994, Environmental Monitoring and Assessment Program: Integrated quality assurance project plan for the surface water resource group: Las Vegas, Nev., U.S. Environmental Protection Agency 600/X-91/080, revision 2.00 .

Heakin, A.J., Neitzert, K.M., and Shearer, J.S., in press, Summary of Environmental Monitoring and Assessment Program (EMAP) activities in South Dakota, 2000-2004: U.S. Geological Survey Scientific Investigations Report 2006-5007.

Omernik, J.M., 1987, Ecoregions of the conterminous United States (map supplement): Annals of the Association of American Geographers, v. 77, no. 1, p. 118-125, scale $1: 7,500,000$.

U.S. Environmental Protection Agency, 1987, Future RiskResearch strategies for the 1990s: Washington, D.C., U.S. Environmental Protection Agency, Science Advisory Board SAB-EC-88-040.

U.S. Environmental Protection Agency, 1998, Environmental monitoring and assessment program (EMAP) Research Plan 1997: Washington, D.C., EPA/620/R-98/002.

U.S. Environmental Protection Agency, 2000, Mid-Atlantic Highlands Streams Assessment: EPA-903-R-00-015, 64 p.

U.S. Environmental Protection Agency, 2002, Biological assessments and criteria-Crucial components of water quality programs: U.S. Environmental Protection Agency Fact Sheet 822-F-02-006, 6 p.

\section{For more information, please contact:}

Director, South Dakota Water Science Center U.S. Geological Survey

1608 Mt. View Road

Rapid City, SD 57703

(605) 394-3200 